MATEC Web of Conferences 6, 05003 (2013)

DOI: $10.1051 /$ matecconf/20130605003

(C) Owned by the authors, published by EDP Sciences, 2013

\title{
Modelling explosive spalling and stress induced thermal strains of HPC exposed to high temperature
}

\author{
J. Ožbolt and J. Bošnjak
}

Institute for Construction Materials, University of Stuttgart, Germany

\begin{abstract}
Permeability of concrete without and with polypropylene fibres is experimentally measured at temperatures up to $300^{\circ} \mathrm{C}$ by employing a new test setup. To investigate explosive spalling of concrete cover numerical modelling is carried out using coupled Thermo-Hygro-Mechanical model oriented towards multi-scale modelling approach. Load induced thermal strains are investigated at meso-scale and it is found that the most part of these strains can be captured by a meso-scale model.
\end{abstract}

\section{INTRODUCTION}

Explosive spalling of high strength and high performance concrete under fire is one of the major concerns in front of the engineering community today. It is associated with violent failure of thin layers of concrete resulting in sudden reduction of load carrying capacity, which may lead to complete collapse. High pore pressures due to low permeability and the thermally induced stresses are considered to be the governing causes of explosive spalling $[1,2]$, however the mechanism has not yet been fully understood.

The most popular method to prevent spalling is the addition of polypropylene (PP) fibres to concrete. It is widely accepted that the PP fibres leave a porous network after melting at around $160^{\circ} \mathrm{C}$, leading to an increase in permeability, thus allowing the water vapour to escape $[3,4]$. The influence of elevated temperature on permeability of concrete is well documented in the literature [3-5]. However, the majority of these tests have been performed on concrete in residual state, i.e. after the specimens were cooled to the room temperature.

This work is aimed at investigating the effect of permeability on explosive spalling of HPC by means of experiment and numerical analysis. A new test setup for permeability measurements at elevated temperatures is developed and validated against the RILEM CEM-Bureau method [6]. HPC without and with PP fibres is tested at temperatures ranging from $20^{\circ} \mathrm{C}$ to $300^{\circ} \mathrm{C}$. The tests were helpful in observing and understanding the beneficial effect of addition of PP fibres in mitigation of explosive spalling. Scanning electron microscope is employed to investigate the changes of the fibre after exposure to elevated temperature.

The numerical modelling of explosive spalling is performed employing the single phase phenomenological thermo-hygro-mechanical model for concrete developed in the framework of three dimensional finite element code MASA [7, 8]. As a constitutive law the temperature dependent microplane model is used. The modelling is performed at meso-scale, where the concrete is modelled as a three phase material comprising coarse aggregates, cement mortar and interfacial transition zone. The influence of permeability on explosive spalling is studied and evaluated. Moreover, the same 3D finite element model was employed to investigate the mechanism that controls the load induced thermal.

This is an Open Access article distributed under the terms of the Creative Commons Attribution License 2.0, which permits unrestricted use, distribution, and reproduction in any medium, provided the original work is properly cited. 


\section{MATEC Web of Conferences}
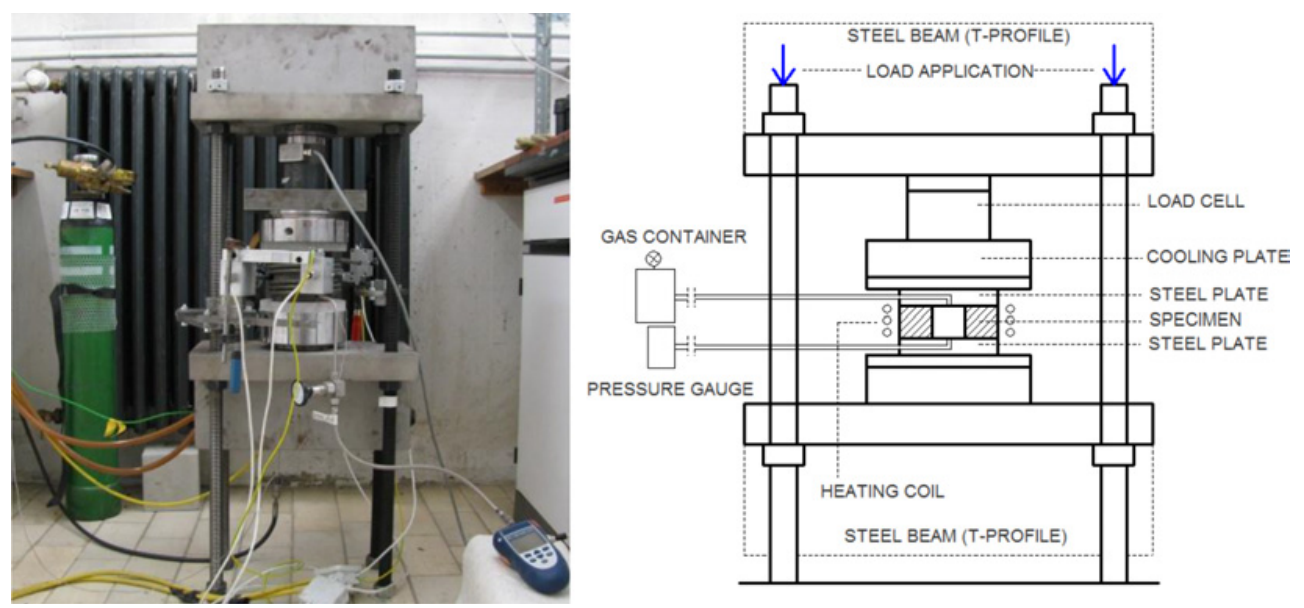

Figure 1. Test new test setup for the permeability measurements at elevated temperatures.

\section{EXPERIMENTAL INVESTIGATIONS}

\subsection{Permeability measurements at high temperature}

A new test setup for measurement of permeability at elevated temperatures is developed and the same is shown in Fig. 1. Specimen used in these tests is hollow cylinder (ring-shaped), which is placed between two steel plates. A graphite sealant with dimensions corresponding to the geometry of the specimen is placed between the plates and the specimen. The setup is insulated using cooling and insulating plates. The applied load is monitored employing a $500 \mathrm{kN}$ capacity load cell. The steel frame consists of two stiff plates and four steel rods. The specimen is heated using a spiral heating collar fastened to the rods.

Around the heating collar, a heat resistant insulation is applied in order to minimize the heat loss to the environment. A heating rate of $0.5^{\circ} \mathrm{C} / \mathrm{min}$ was selected to avoid possible cracking due to thermal gradients. Nitrogen is used as permeating gas, owing to its inert behaviour with respect to concrete and because it does not enhance burning. Once a pressure of $20 \mathrm{MPa}$ is applied, the initial permeability measurement is performed at room temperature. The hollow portion of the specimen is pressurized using nitrogen and the pressure is measured. Maximum applied pressure is $11 \mathrm{bar}$, while the minimum is $2 \mathrm{bar}$ (both gauge pressure). The pressure history is obtained and apparent permeability for every time step is calculated using the following expression derived from Darcy's and Clapeyron's law:

$$
k=\frac{\eta \ln \left(\frac{r_{2}}{r_{1}}\right)}{\pi H} \frac{\frac{\Delta p}{\Delta t} V}{\left(p_{2}^{2}-p_{1}^{2}\right)} .
$$

Where: $k\left[\mathrm{~m}^{2}\right]=$ permeability, $\eta\left[\mathrm{Ns} / \mathrm{m}^{2}\right]=$ viscosity of the permeating fluid, $r_{1}[\mathrm{~m}]=$ inner radius of the specimen, $r_{2}[\mathrm{~m}]=$ outer radius of the specimen, $H[\mathrm{~m}]=$ height of the specimen, $p_{1}[\mathrm{~Pa}]=$ inlet pressure, $p_{2}[\mathrm{~Pa}]=$ outlet pressure (atmospheric pressure), $V\left[\mathrm{~m}^{3}\right]=$ volume of the pressurized gas. In each time interval $\Delta t$, the apparent permeability $k$ is calculated according to Eq. (1). Pressure decay history is obtained from the experiment. Intrinsic permeability is evaluated employing the Klinkenberg method [9]. In case of specimens tested at elevated temperature, once the specimen attained the desired temperature, three or more permeability tests are performed following the above-described procedure and the specimen is heated to the next target temperature. The permeability measurements in case of specimens without fibres are carried out at temperature levels: $20^{\circ} \mathrm{C}, 80^{\circ} \mathrm{C}, 150^{\circ} \mathrm{C}, 200^{\circ} \mathrm{C}$ and $300^{\circ} \mathrm{C}$. A few more measurements are made in case of specimens with fibres to cover the region around the 


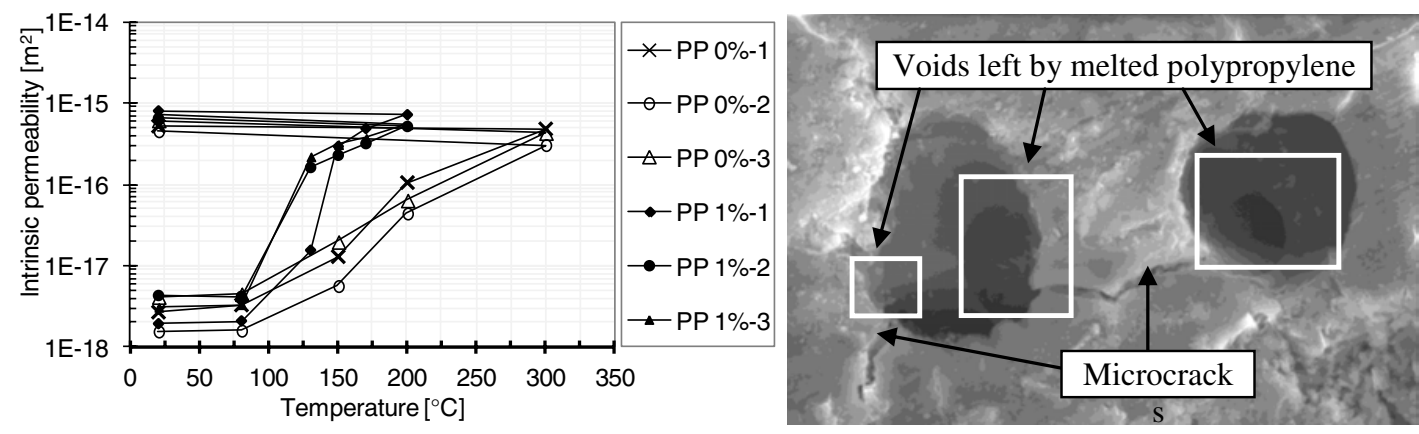

Figure 2. Intrinsic permeability as a function of temperature (left) and SEM photos of the concrete with PP fibres after exposure to $200^{\circ} \mathrm{C}$ for 2 days (right).

melting point of fibres, i.e. measurements are also performed at $130{ }^{\circ} \mathrm{C}$ and $170{ }^{\circ} \mathrm{C}$. Upon finishing the test series at elevated temperatures, the specimen is gradually cooled to the room temperature. Residual permeability measurements are performed after the specimen was kept at room temperature for at least 12 hours.

High performance concrete (grade C80/88) without and with PP fibres with a maximum aggregate size of $8 \mathrm{~mm}$ was used. The cubic compressive strength at the time of testing was approx. $90 \mathrm{MPa}$. Concrete with PP fibres contained $1 \mathrm{~kg} / \mathrm{m}^{3}$ of fibres. The performance of the same concrete was experimentally investigated under ISO 834 curve [10] and it was found that the addition of PP fibres mitigates explosive spalling.

\subsection{Experimental results on permeability}

The relation between measured permeability and temperature for the two investigated concrete types is plotted in Fig. 2 (left). It can be observed that concrete without addition of PP fibres exhibits a steady rise in permeability with increasing temperature. The average permeability for plain concrete at $20^{\circ} \mathrm{C}$ is obtained as $2.6 \times 10^{-18} \mathrm{~m}^{2}$. Up to $80^{\circ} \mathrm{C}$ there is no significant increase in permeability. Beyond $80^{\circ} \mathrm{C}$, there is almost a linear increase in permeability with rise in temperature (semi-log scale). After reaching a temperature of $200^{\circ} \mathrm{C}$, permeability increased by approximately 20 to 30 times, whereas at $300{ }^{\circ} \mathrm{C}$ there was an increase in permeability of two orders of magnitude as compared to the value at room temperature. Residual values obtained on specimens cooled to the room temperature are approx. 10-25\% higher than the values obtained at the elevated temperatures.

In case of concrete with PP fibres, at temperatures up to $80^{\circ} \mathrm{C}$ the permeability is found to be very similar to the concrete without fibres. However, at temperatures above $80^{\circ} \mathrm{C}$ concrete with fibres exhibits a sudden jump in permeability of almost two orders of magnitude. At $150{ }^{\circ} \mathrm{C}$, the difference between the two concrete types is almost two orders of magnitude. Beyond $170^{\circ} \mathrm{C}$, the rate of permeability increase roughly corresponds to that of concrete without fibres. Same as for the concrete without fibres, the residual permeability values of concrete with fibres are found to be higher than the permeability values at elevated temperatures. These results clearly demonstrate that there is a significant increase in the permeability of concrete with PP fibres in temperature range between $80^{\circ} \mathrm{C}$ and $130{ }^{\circ} \mathrm{C}$. This is considered to be the major reason for the beneficial effect of addition of PP fibres in mitigation of explosive spalling.

It is generally considered that the empty fibre beds form an interconnected network of empty pores and lead to a rise in permeability. However, these experimental data show that the permeability increase takes place at temperatures much lower than the melting point of fibres $\left(160^{\circ} \mathrm{C}\right)$. Hence, the results suggest that the melting of fibres is not the only mechanism responsible for the permeability increase. 

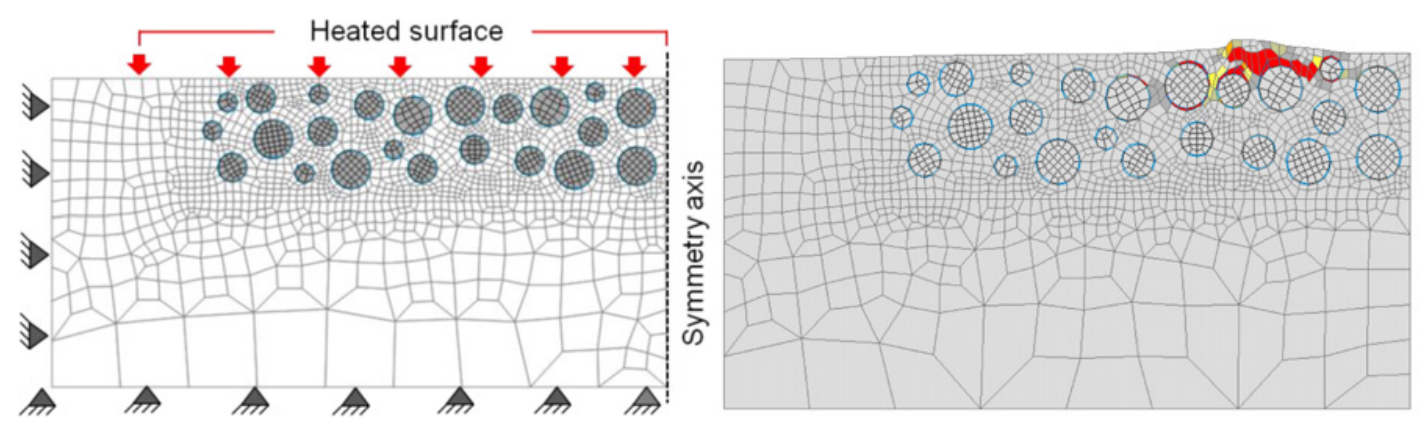

Figure 3. Geometry and boundary conditions (left) and failure mode corresponding to permeability of $6 \times$ $10^{-15} \mathrm{~m} / \mathrm{s}$ (right).

Fibres lose their thermal stability at around $120^{\circ} \mathrm{C}$, which results in a significant decrease in elasticity modulus. They become softer and more susceptible to change of shape. One of the possible explanations for the sudden rise in permeability is that the pressurized gas compresses fibres and creates a path between concrete and fibre surface.

In order to provide more insight into the behaviour of fibres at temperatures around melting point, SEM photos of the concrete specimen containing PP fibres were made after the concrete was exposed to $200^{\circ} \mathrm{C}$ for two days (Fig. 2). As can be seen, the volume of the polypropylene in the pore is reduced, since part of the polypropylene is transported into the micro-cracks in the cement matrix. Small dark portions (marked rectangles in Fig. 2) represent the voids created by melting of polypropylene. However, no such change could be observed in the parts of the fibre not surrounded by micro-cracks. This implies that the cement matrix is not capable of absorbing the fluid polypropylene. Similar photos were made for the exposure duration of 20 minutes, and no change of PP fibres was noticed, thus demonstrating that the melting of fibres is a time dependent phenomenon which is not likely to fully take place during short fire exposures.

\section{NUMERICAL INVESTIGATIONS}

\subsection{Effect of permeability on explosive spalling - meso-scale modelling approach}

Numerous experiments [1-5] demonstrated certain aspects of explosive spalling. However, only limited information can be deduced due to the inherent difficulties in such experiments. On the other hand, numerical analysis can provide much more detailed insight into the problem. Therefore, the problem of explosive spalling is numerically analysed employing the Thermo-Hygro-Mechanical (THM) model with temperature dependent microplane model as constitutive law for concrete $[7,8]$. The concrete was discretized as three phase material comprising of coarse aggregates, cement mortar and an interfacial transition zone between the two. Under assumption of plane strain condition, a slice of a concrete specimen was simulated. The advantage of symmetry was taken and only half of the geometry was modelled. The geometry and the boundary conditions are shown in Fig. 3 (left). One sided heating corresponding to ISO 834 fire curve is applied.

The analysis is carried out for different values of relative permeability $\left(\mathrm{a}_{0}\right)$ viz. $6 \times 10^{-16} \mathrm{~m} / \mathrm{s}$, $2 \times 10^{-15} \mathrm{~m} / \mathrm{s}, 6 \times 10^{-15} \mathrm{~m} / \mathrm{s}, 2 \times 10^{-14} \mathrm{~m} / \mathrm{s}, 4 \times 10^{-14} \mathrm{~m} / \mathrm{s}, 8 \times 10^{-14} \mathrm{~m} / \mathrm{s}$ and $2 \times 10^{-13} \mathrm{~m} / \mathrm{s}$. The relative humidity of the material is kept at approximately $70 \%$ and other material properties are kept constant for all investigated cases. The typical failure mode corresponding to $\mathrm{a}_{0}=6 \times 10^{-15} \mathrm{~m} / \mathrm{s}$ is shown in Fig. 3 (right). It can be observed that the failure occurs locally and at a relatively low depth, typical for explosive spalling. 


\section{IWCS 2013}
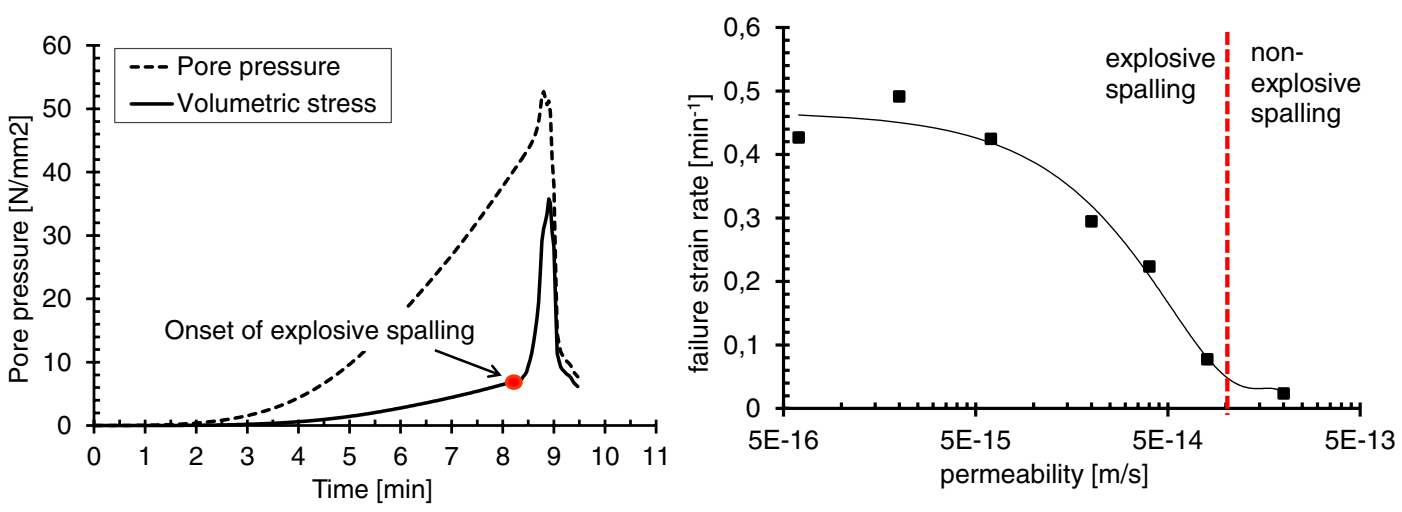

Figure 4. Development of pore and volumetric pressure in the critical element with time (left) and the influence of permeability on volumetric stress at failure (right).
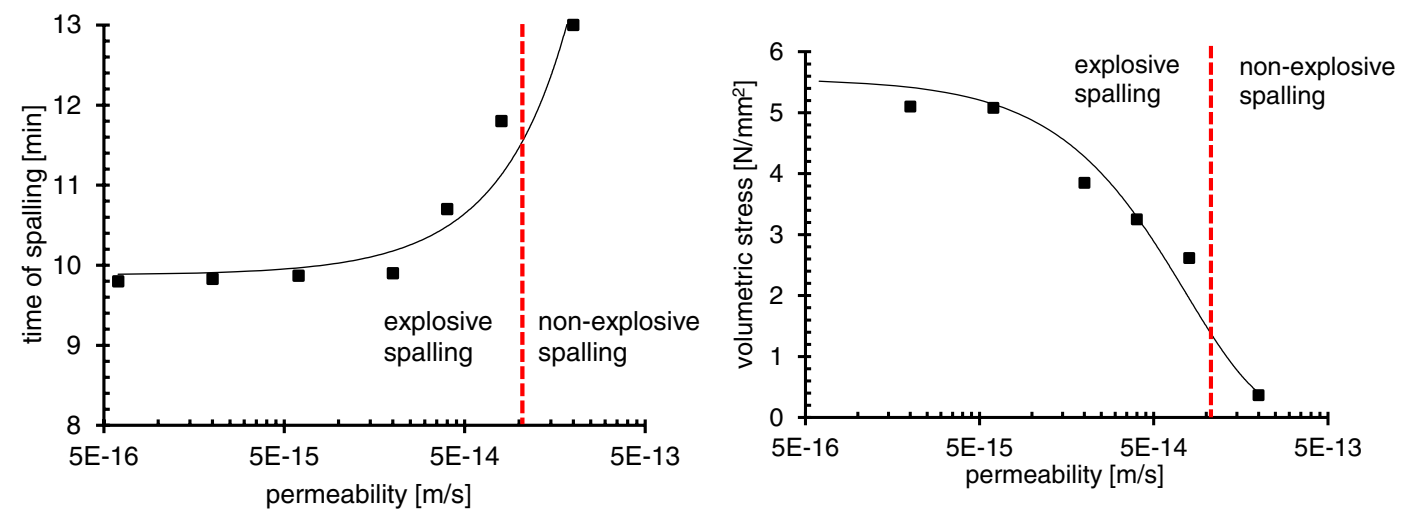

Figure 5. Influence of permeability on time of spalling (left) and volumetric stress (right).

The development of pore and volumetric pressure in the critical element (where the damage localizes) with time is shown in Fig. 4 (left). The pore pressure is calculated in the THM model, while the volumetric pressure is derived by multiplying the pore pressure with the porosity [7]. It can be observed that the onset of explosive spalling is demarcated with a sudden increase of volumetric pressure, Fig. 4 (left).

The series of analyses are evaluated to obtain the influence of permeability on (i) strain rate at failure; (ii) initiation time of explosive spalling; and (iii) volumetric pore pressure corresponding to the onset of explosive spalling. Fig. 4 (right) shows the variation of failure strain rate with increasing permeability. In the case of relatively low permeability, the failure strain rate is very high, indicating the violent nature of explosive spalling. On the other hand, when permeability increases for approximately two orders of magnitude, the failure strain rate decreases significantly, indicating less violent failure. This type of failure is associated rather with thermally induced non-explosive damage than with explosive spalling.

The influence of permeability on time of spalling is plotted in Fig. 5 (left). The time of spalling is almost constant for low permeability values, whereas it increases as permeability rises. It can be concluded that the failure mechanism for permeability higher than $5 \times 10^{-14} \mathrm{~m} / \mathrm{s}$ can be mainly attributed to non-explosive spalling caused by thermal stresses, whereas lower permeability values result in explosive spalling. These findings are consistent with the experimental results, which showed that the addition of polypropylene successfully mitigates explosive spalling [10]. Furthermore, permeability 
MATEC Web of Conferences

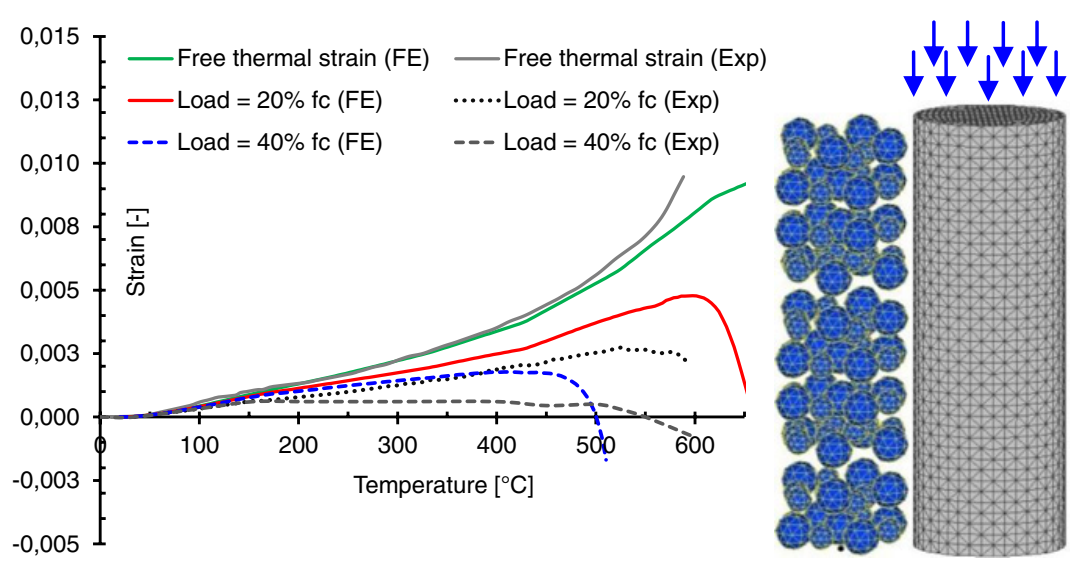

Figure 6. Experimentally [12] and numerically obtained development of longitudinal strains with increasing temperature (left); finite element mesh (right).

measurements discussed above showed that the addition of fibres results in a permeability increase of approximately two orders of magnitude.

The variation of volumetric stress at failure with respect to permeability is shown in Fig. 5 (right). A gradual decrease of volumetric stress at failure with increasing permeability is observed. Since the volumetric stress at failure changes with permeability, it can be inferred that a certain level of thermal stresses is essential for explosive spalling. Pore pressure (volumetric stress) acts as a trigger of the explosive spalling and only in combination with thermal stresses can lead to explosive spalling. Further analysis of the same example with the thermo-mechanical (TM) model (no pore pressure) [7] instead of the THM model confirmed that the thermal stresses alone can result only in non-explosive type of spalling, i.e. thermally induced damage. In this case the failure strain rate is extremely low and the crack takes several minutes to open to the critical width.

\subsection{Modelling load induced thermal strains on meso-scale}

Concrete exhibits a phenomenon of load induced thermal strains (LITS) when heated in loaded state [11]. These strains are typically explicitly defined in the most of thermo-(hygro)-mechanical models [7]. However, when modelling concrete at meso-scale, it is assumed that the effect of LITS should mainly result as a consequence of inhomogeneity of concrete structure and should, therefore, not be explicitly accounted for.

The experiments performed by Hager [12] are simulated by employing meso-scale model without predefinition of LITS. Some of the tested loading scenarios included heating of not loaded concrete and heating of preloaded concrete (loading rates of $20 \%$ and $40 \%$ of the compressive strength) with relatively moderate heating rates of $1{ }^{\circ} \mathrm{C} / \mathrm{min}$. The comparison between experimental and numerical results is presented in Fig. 6 (longitudinal strain vs. temperature). Unloaded concrete exhibits only expansion during heating, whereas preloaded concrete experiences a reduction in longitudinal strain in comparison with free thermal strain.

When concrete is loaded in compression (in the longitudinal direction) and the load is kept constant throughout the heating stage, the material tends to expand more in lateral than in longitudinal direction. The damage due to mechanical loading is further aggravated by heating. Since aggregates and cement mortar have different mechanical and thermal properties, the incompatibility of the two materials leads to thermo-mechanical damage. Overall results indicate that the thermo-mechanical model at meso-scale 

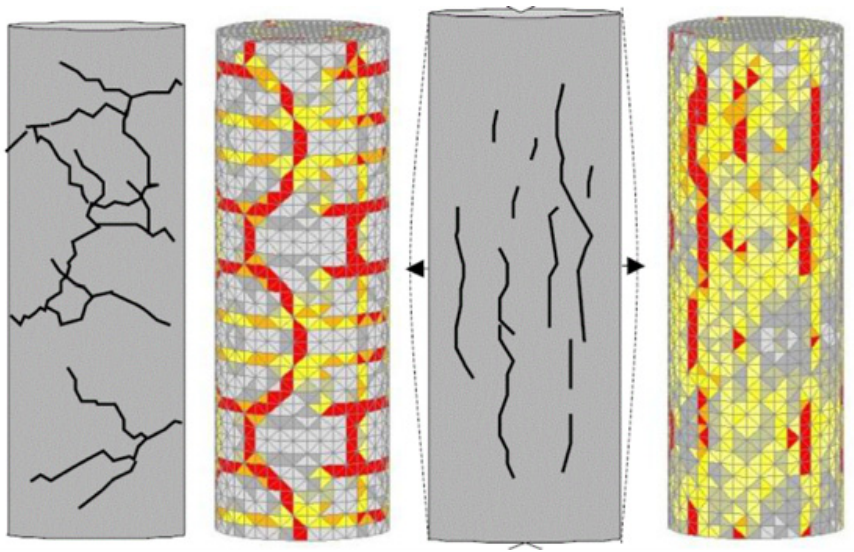

Figure 7. Experimentally [12] and numerically obtained failure modes: concrete heated to $600{ }^{\circ} \mathrm{C}$ (left) and concrete loaded to $20 \% \mathrm{f}_{\mathrm{cc}}$ and subsequently heated to $600^{\circ} \mathrm{C}$ (right).

can capture the behaviour of loaded and subsequently heated concrete without prior definition of load induced thermal strain.

Differences in the experimental and numerical results mainly occur since the model cannot fully capture the dehydration of cement paste at temperatures up to approximately $250^{\circ} \mathrm{C}$. It was recently shown by Mindeguia et al. [13] that dehydration of cement paste plays an important role in the development of LITS at lower temperatures. However, the numerical results indicate that for practical applications the response of the meso-scale model is reasonably realistic, i.e. the major phenomena governing LITS seems to be the thermo-mechanically induced damage of cement past.

Typical failure mode for concrete heated up to $600^{\circ} \mathrm{C}$ and concrete loaded up to $20 \%$ of $\mathrm{f}_{\mathrm{c}}$ prior heating to $600^{\circ} \mathrm{C}$ are shown in Fig. 7. In the case of not loaded concrete the cracking takes place randomly over the cylinder surface, since concrete undergoes expansion in all directions. Random pattern of the surface cracks is nicely captured using the meso-scale model. Loaded specimen, on the other hand, exhibits different kind of failure mode with cracks running parallel to the loading direction, indicating the effect of preloading. It is evident that the meso-model can realistically capture the failure mode of concrete under thermal loading, without and with prior mechanical loading.

\section{CONCLUSIONS}

In this work the phenomenon of explosive spalling is experimentally and numerically investigated, with emphasis on influence of permeability. A new experimental setup for measurement of concrete permeability at high temperature is presented. It is employed in the permeability measurements of HPC without and with PP fibres $\left(1 \mathrm{~kg} / \mathrm{m}^{3}\right)$ at temperatures up to $300^{\circ} \mathrm{C}$. Plain HPC exhibited a steady permeability increase with rising temperature, whereas HPC with PP fibres experienced a sudden jump in permeability at temperatures between $80^{\circ} \mathrm{C}$ and $130^{\circ} \mathrm{C}$. The results indicate that the melting of fibres may not be the only mechanism leading to the sudden permeability increase, since fibres melt at $160^{\circ} \mathrm{C}$. Numerical analysis is carried out at meso-scale by employing coupled thermo-hygro-mechanical model. The influence of permeability on explosive spalling is investigated in detail and it is found that lower permeability leads to a higher risk of explosive spalling. The numerical results exhibit a very good agreement with the experimental observations. The main reason for explosive spalling is found to be pore pressure, which acts as a trigger and only in combination with thermal stresses can cause explosive spalling. The numerical studies indicate that LITS can be predicted automatically using meso scale 


\section{MATEC Web of Conferences}

model for concrete. The main source of LITS seems to be the thermo-mechanically induced damage of cement paste.

\section{References}

[1] Connolly, R.J., The spalling of concrete in fires, PhD Thesis, Aston University, 1995.

[2] Khoury, G.A., Effect of fire on concrete and concrete structures, Progress Struct Eng Mat, 2, 429-447, 2000.

[3] Kalifa P., Chene G. and Galle C., High-temperature behaviour of HPC with polypropylene fibers: From spalling to microstructure, Cem Concr Res, 31, 1487-1499, 2001.

[4] Zeiml M., Leithner D., Lackner R. and Mang H.A., How do polypropylene fibers improve the spalling behaviour of in-situ concrete. Cem Concr Res, 36, 29-942, 2006.

[5] Zeiml M., Lackner R., Leithner D. and Eberhardsteiner J., Identification of residual gas-transport properties of concrete subjected to high temperatures, Cem Concr Res, 38, 699-716, 2008.

[6] Kollek J.J., The determination of permeability of concrete by CEMBureau method: a recommendation, Mater Struct, 22, 225-230, 1989.

[7] Periškić G., Entwicklung eines 3D thermo-hygro-mechanischen Modells für Beton unter Brandbeanspruchung und Anwendung auf Befestigungen unter Zuglasten, $\mathrm{PhD}$ Thesis, University of Stuttgart, 2009. [in German]

[8] Ožbolt J., Li Y.J. and Kožar I., Microplane model for concrete with relaxed kinematic constraint, Int J Solids Struct, 38, 2683-2711, 2001.

[9] Klinkenberg L.J., The permeability of porous media to liquids and gases, American Petroleum Institute, Drilling Production Practice, 200-213, 1941.

[10] Bošnjak J., Ožbolt J., Sharma A. and Periškić G., Permeability of concrete at high temperatures and modelling of explosive spalling, Proceedings of FraMCoS-8, Van Mier, Ruiz, Andrade, Yu and Zhang (Eds), Toledo, Spain, 11/3-14/3, 2013.

[11] Khoury G.A, Strain of heated concrete during two thermal cycles - Parts 1,2 and 3, Mag Concr Res, 58, 367-385, 387-400 and 58, 421-435, 2006.

[12] Hager I., Propriétés mécaniques des bétons à haute performanceà haute température - évolution des principales propriétés mécaniques, PhD Thesis, Ecole Nationale des Ponts et Chaussées, 2004. [in French]

[13] Mindeguia J-C., Hager I., Pimienta P., Carre H., Borderie C., Parametric study of transient thermal strain of ordinary and high performance concrete, Cem Concr Res, 48, 40-52, 2013. 